\title{
WHO moves to classify traditional medicines
}

$\mathrm{T}$ he World Health Organization (WHO) will create a web-based classification system for traditional medicines to help bring them out from "the dark side of the planet of health information."

The project will hopefully lead to greater recognition of traditional healing techniques and more objective research into their efficacy, adds Dr. T. Bedirhan Üstün, who's heading the project to develop the international information standards. "Now we at WHO collect information on Western medicine care and we turn a blind eye totally to traditional medicine care, but at least 30\%$40 \%$ of care is delivered in a traditional medicine setting."

Üstün hopes the initiative will begin to bridge the divide between traditional and Western medicine that is evident even in countries in which traditional medicine is widely-practiced. "There is an ongoing practice in China, for example, when you enter the hospital, you turn right you get Western medicine care, you turn left you get traditional medicine care."

But Üstün stresses that the creation of a classification system for traditional medicine practices does not constitute an endorsement of their use, though it may promote research that ultimately provides evidence to support such use.

The WHO's foray into the area will initially be limited. "We are differentiating between folk medicine and traditional medicine," Üstün says. Traditional medicines have longstanding histories with nationally applied, written standards and a systematic approach, he explains. "We are not dealing with snake oils, hocus pocus type of magical [practices]."

WHO will also focus initially on developing information standards for traditional medicine practices in China, Japan and Korea, as they have a long history of use and higher level of standardization in comparison with other nations.

A second module could conceivably focus on medicines from the Indian

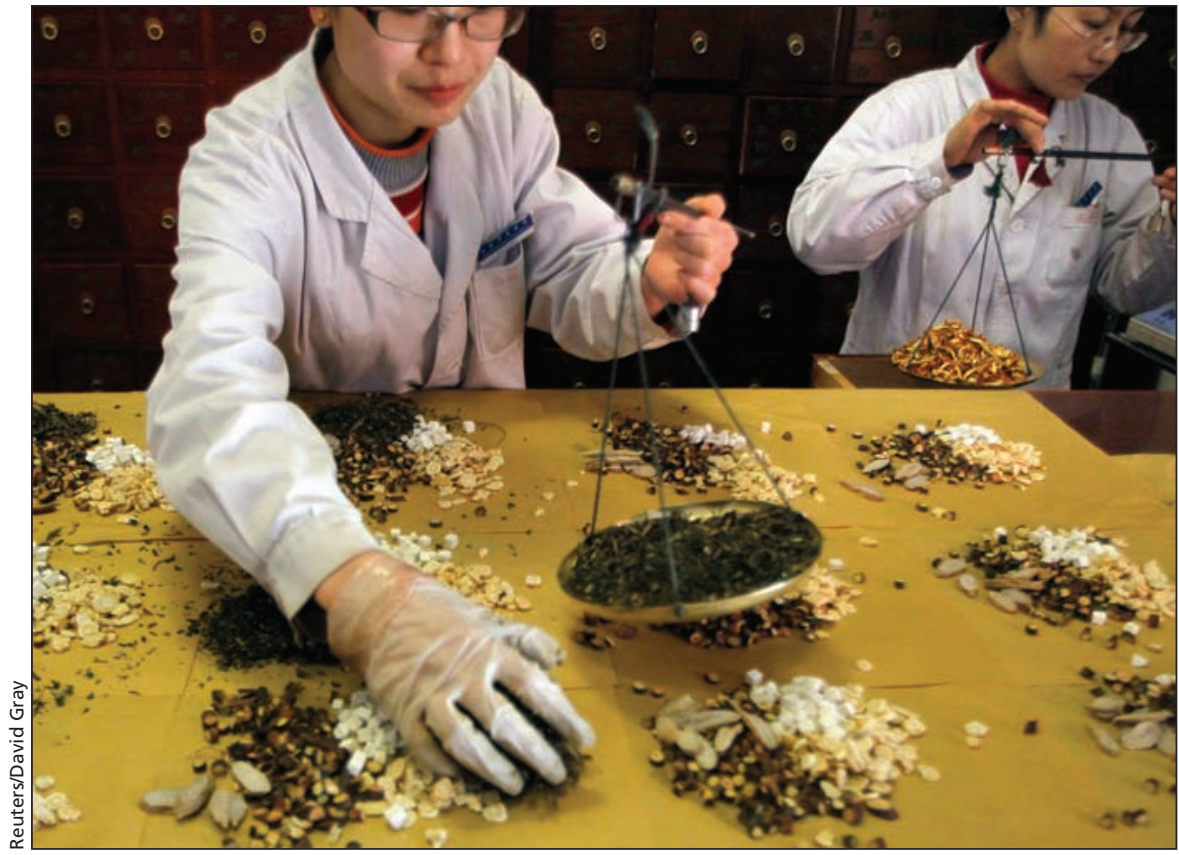

Workers prepare prescriptions at the Capital Medical University Traditional Chinese Medicine Hospital in Beijing, China.

subcontinent, and a third on those from other parts of the world.

There is increasing interest within the Canadian academic and pharmaceutical communities about traditional Chinese herbal medicine. The Canadian Institutes of Health Research, for example, is embarking on joint projects with the government of China to determine the therapeutic efficacy of various herbal compounds (www.cmaj.ca/cgi /doi/10.1503/cmaj.109-3106).

There also appears to be growing interest among patients in using such alternative therapies as Chinese traditional medicine, Kampo medicine from Japan, Ayurvedic medicine from the Indian subcontinent, Western herbal or botanical medicine and Native American medicine.

Traditional medicine has become very popular, says Heather Boon, founding chair of the Canadian Interdisciplinary Network for Complementary and Alternative Medicine Research. "Right now, anything Asian is trendy. We're all eating sushi, we're feng shuiing our houses."
"A lot of people see these therapies as gentle, as being more holistic practitioners that spend more time with them, that listen to them, that help them with conditions or feelings or issues that Western medicine either can't define or doesn't define as an illness."

Nevertheless, many Western physicians still question the value of traditional medicines, Üstün says. "I find this is a healthy skepticism. But I wouldn't outrightly put it as an ideological basis to reject [traditional medicine] as nonscientific."

"Healthcare providers in general are kind of in a tough spot," Boon says. The lack of evidence makes it hard for doctors to recommend traditional medicines but at the same time, when they hear their patients talk about how the therapies have helped, doctors are reluctant to curb their use. "A lot of doctors are kind of saying: well, I can't recommend it, but if you really want to use it, I'm not going to say 'Don't' either."

"What we need to know is what works for whom in what conditions and exactly what interventions or what 
component of the interventions work best," she adds.

Boon calls a standardized classification system a good first step, if only because it's a start toward defining the exact nature of traditional practices. "I think anything that can provide clarity and allow for comparison across studies would be helpful."

Practitioners of traditional medicines are, of course, of the opinion that they are underrecognized and undervalued.

That's largely a function of a lack of awareness, says Mary Xiumei Wu, president of the Toronto School of Traditional Chinese Medicine. "People don't know about it so they are not open-minded."

In Canada, there is "not too much recognition" of Ayuvedic practices, says Rakesh Madi, president of the International Council of Ayuvedic Physicians Inc.

Others, such as Mary Watterson, doctor of traditional Chinese medicine and registrar of the College of Traditional Chinese Medicine Practitioners and Acupuncturists of British Columbia, says that traditional medicines have already entered "the mainstream of the Canadian health care system," and concerns about their lack of an evidence base have dissipated.

In British Columbia, which is the only province to formally recognize and regulate traditional Chinese medicines in Canada, there are 1500 registered practitioners and 300 more people studying to become accredited, Waterson writes in an email. "Not only am I not aware of a 'stigma' but there is a continued and significant increase in members of the public seeking treatment from TCM/A [Traditional Chinese Medicine/Acupuncture] practitioners. I cannot speak for other traditional medicines, but certainly in its journey from Asia TCM/A is experiencing a growing demand within the western world including Canada, USA, Europe and Australia."

The WHO's classification platform will be similar to a model developed at Stanford University in Palo Alto, California, that organizes information into "principled ontologies," which are defined not as states of being, but rather, as hierarchical groupings of biomedical knowledge that contain all relevant enti- ties and their relationships (http://bmir .stanford.edu/file_asset/index.php/1298 /BMIR-2008-1298.pdf).

Language is expected to be one of the biggest challenges.

For example, there is considerable disagreement about the English translation of certain terms in traditional Chinese medicine, Watterson says. "In 1980, China put out their first book in English. Ever since then there's been no standardized translation of those terms."

But resolving language issues could boost the recognition of traditional Chinese medicine around the world, says Mina Larson, communications director for the National Certification Commission for Acupuncture and Oriental Medicine, which regulates traditional Chinese medicine in the United States. "If we want to have this medicine recognized globally and mainstream it, we have to come into agreement with codes and with language. And the WHO has to be the organization that has to basically put it all together for us." - William Burr, Ottawa, Ont.

CMAJ 2011. DOI:10.1503/cmaj.109-3761 